\title{
Blackened Audiotopia: Privatized Listening and Urban Experience
}

\section{Key words}

Black metal, Ideology, Ipod Culture, Headphone Culture, Urban studies, Fan studies.

\begin{abstract}
In the age of headphone culture, where privatized listening while wandering around the city is the norm, the use of headphones raises questions about the experience of the listener and their perception of their urban environment. Of particular interest, is the disjunct relationship between black metal music and urban space. Black metal lyrics often portray images of nature and paganism, a concept completely removed from a modern urban landscape. This paper draws from Michael Bull's work on iPod culture as well as ethnographic research to explore the black metal fan's experience of private listening in a public cityscape. The main focus of this study is the relationship between the ambiguously intertwined visual urban reality and sonic imaginary. The research suggests that the black metal listener can have one of four experiences of time and space resulting in what is referred to as either a split or blend of the aural imagined experience and the visual reality of the city.
\end{abstract}

'Black Metal has always been an artistic mode that shuns the crowded cityscape, seeking refuge in the natural world, and we embrace this both lyrically and visually'. (Raedwalh of Wodensthrone in Itkowitz 2010)

There is no one way to define the values and aesthetics which are inherent in black metal culture. The complexity of the genre, which is defined by three waves, and numerous subgenres has a variety of fans whom each authenticate certain values over others. The main ideologies that are associated with black metal are that of nihilism, misanthropy and individualism. These concepts are developed lyrically through the primary themes of nature, satanism and (often nationalistic) paganism. Despite the genre's complexity, what is clear, is that black metal music cannot be separated from its ideologies including those that help determine the visual culture and the symbols/images which reflect them (Hagen 2011, Patterson 2013, Venkatesh et al 2014, Moynihan and Søderlind 1998)

David Prescott-Steed in a paper (2013) published by black metal journal Helvete, presents the notion of blackened walking, a concept which defines listening to black metal music while walking in everyday life. Whilst justifying this concept, he demonstrates how walking is an important part of black metal visual culture, referring to two documentaries in which legendary black metal musicians are pictured walking through Norwegian landscapes. In both examples, the musicians on their contrasting journeys evoke a meaningfulness towards isolation and self-authenticity, demonstrating a link between walking and black metal ideology. PrescottSteed, through these examples, illustrates 'the capacity of walking to communicate a deeply planted Black Metal aesthetic' (Prescott-Steed 2013: 47).

In an age of what I shall be terming 'headphone culture' (a development of Michael Bull's work on Ipod Culture, as we move towards the use of smartphones with headphones as the primary 
mode of privatized listening) where listening to music while walking through a city has become the norm, the notion of blackened walking raises questions about how blackened walkers encounter different experiences of the modern city. Black metal's strong connection to ideology and signification further complicates the notion of blackened walking. The walker's mind may become occupied by these concepts and images, changing their perception of the city through the enhancement of emotion and imagination.

With the intention of exploring the blackened walker's personal experience of private listening in a public cityscape, I have utilized a qualitative online survey. Using narratives of blackened walkers, I have investigated the relationships between the listener, the sound world and the visual world. As the blackened walker travels through the city, their sound world is blaring black metal music while their visual world depicts the ordinary urban. The images conjured from the music and the reality of the images observed are often perceived as antithetical to one another. The main focus of my research is this relationship between the ambiguously intertwined visual urban reality and sonic imaginary. The visual urban reality defines the city that the headphone user sees around them, their reality, and the sonic imaginary describes the music that they hear which affects their imagination. My research has suggested that the blackened walker can have one of four experiences of time and space resulting in what I refer to as either a split or a blend of the aural imaginary and urban material reality. The blackened walker can either blend the worlds experiencing either a transformed real or an aestheticized real, or split them experiencing an unconscious imagined or a lucid imagined. These experiences are not necessarily mutually exclusive, a blackened walker may experience a combination of blend and split, real and imagined, or a fusion of the various experiences in any sequence. In the figure below I have laid out each of these terms and their explanations.

\begin{tabular}{|l|l|}
\hline BLEND & \\
\hline Aestheticized real & $\begin{array}{l}\text { The walker aestheticizes the city, enhancing } \\
\text { their perception of it. }\end{array}$ \\
\hline Transformed real & $\begin{array}{l}\text { The walker transforms the city, with music } \\
\text { induced fantasies. }\end{array}$ \\
\hline SPLIT & $\begin{array}{l}\text { The walker 'spaces out', unconsciously } \\
\text { entering and exiting their own imagination in } \\
\text { a manner that minimizes their attention to the } \\
\text { urban material reality. }\end{array}$ \\
\hline Lucid Imagined & $\begin{array}{l}\text { The walker consciously enters their } \\
\text { imagination, fantasizing a different landscape } \\
\text { or image than the one before their eyes. }\end{array}$ \\
\hline
\end{tabular}


Figure 1: Four experiences of the relationship between sonic imaginary and visual urban reality.

These categories of the relationship between sonic and visual help to analyse and explain the differing experiences of blackened walkers, showing how music can affect the fan in daily life.

\section{Methodology}

I conducted an online survey of ten questions, distributed on social media through my own personal Facebook account, the account of an existing contact from Groningen in the Netherlands, as well as Facebook groups 'UK Black Metal' and 'Black Metal Purgatory' which have the combined reach of 9,798 members. The survey generated seventy-six responses from individuals who self-identify as black metal fans living in a city. Participants are from a variety of countries and cities, the majority being from the UK (forty participants) second to the UK was the twenty-five respondents from the Netherlands (sixteen of which are from Groningen) leaving five from the USA, three from Germany, and one each from Sweden, Denmark and India. The purpose of this research was to gain general information about the private listening experience of the black metal fan in the city. Due to this, the survey was not specific in terms of gender, race, ethnicity, age or class and none of these aspects were collected as data.

Participants were asked how, when and where they listen to black metal music, followed by whether they listen to music while 'on the go' or when walking or cycling. $94.67 \%$ of the respondents confirmed that they do listen to black metal while on the go, while $93.24 \%$ claimed to walk or cycle while listening. Thus, $94 \%$ of the respondents engage in some form of blackened travelling.

\section{Black Metal Ideology in Headphone Culture}

Research into private listening varies drastically from ethnographic research into the bedroom listening of vinyl records and case studies on the Walkman, to subcultural fan studies and analyses of iPod culture. Michael Bull in his book 'Sound Moves: iPod Culture and urban experience' (2007) suggests two perspectives of iPod culture: a Bergsonian act of liberation and an Adornoian act of colonization. The former presents the optimistic ideology of the iPod user as having cognitive freedom and an increased control over space. The latter pessimistically refers to the iPod user as a symbol of conformism and one dimensionality whose reliance on a mediated experience highlights the 'fetishizing role of music in the management of contemporary urban experience' (Bull 2007: 122). My research resonates more closely with the Bergsonian perspective, suggesting that blackened walkers are not conforming to modern society, but adapting to its symptoms either by blocking out noisy cities (splitting the sonic and the visual) or enhancing their urban environment (blending the sonic and the visual).

In conjunction with these theories Bull presents his concept of audiotopia, 'Audiotopia comprises the desire for immersive auditory experience whereby the users' chosen soundworld eradicates the preexisting soundworld that users inhabit' (Bull 2012). The audiotopia is an experience inherently connected to private listening in a public space. It describes the intense pleasure that the iPod user enjoys when travelling through the city, as it enables the user to block out the external environment both sonically and, as I will argue, mentally. Bull uses this concept of audiotopia to illustrate the toxic pleasures of iPod listening, claiming that iPod use becomes 
addictive, antisocial and eventually physically harmful (hearing damage). Despite Bull's emphasis on toxicity, he does, however, explore the many positive effects of iPod culture.

Bull's work examines the iPod users control of the sonic environment and the cognitive effects of this control. iPod users sonically control their environment by blocking out external noise for the purpose of mood maintenance. There are several effects that Bull presents: minimizing stress of a busy urban environment, desire for a particular feeling (such as nostalgia, calm, happiness etc.) and individual empowerment. Each of these cognitive effects were present in the responses of my survey, participants reported both consciously and subconsciously listening to black metal for a particular cognitive experience.

While almost all iPod users claim a desire for blocking out external noise, the reasons behind their decision differs from user to user. The psychological benefit of individual empowerment was a popular effect among blackened walkers. Several survey participants mentioned feeling powerful or linking the music with solitude and concentrating on the self. This may be due to the notion of individualism present in black metal ideology. Black metal Individualism is realized through Satanism and depicted through isolation of bleak landscapes. In the paper 'Eschewing Community' (2014) Vivek Venkatesh (et al,) present the black metal fan as an individual who eschews community and welcomes solitude. The research draws its conclusions from interviews as well as from black metal documentaries involving established musicians. In this paper, listening and appreciating black metal music is perceived, by the participants, as an individual and personal activity. This is exemplified by one particular respondent who states:

'...black metal appreciation is done on an individual level [with] solitude [in] peace and quiet...ideally, there should not [even] be any black metal shows [because] it needs to be appreciated at an individual level!' (Venkatesh et al 2014).

The sense of the individual is linked with empowerment of the self that is central to black metal ideology, along with self-reliance and solitude. Front man, Gaahl of Gorgoroth reveals his personal understanding of individualism in the documentary True Norwegian Black metal (VICE 2011) where he declares that one should only worship the 'God within yourself, because that's the only true God'. Here Gaahl is emphasizing the importance of self-reliance, of not following the universal God but the God within the individual. With the emphasis on individualism in black metal, it is unsurprising that the participants of the survey claimed feelings of isolation and self-empowerment as either a conscious or subconscious aim of blackened walking.

The reason for desiring control for one's sonic environment is not always its cognitive affect. Some individuals seek escapism or even isolation through blocking out the external noise of the people around them. Misanthropy is another value attached to black metal ideology. This hatred of humankind may act as a form of motivation to impede human interaction through control of the sonic environment. In his book on extreme metal, Kahn-Harris ties together misanthropy and individualism under what he terms black metal satanic ideology (Kahn-Harris 2007: 40). Here the importance of the self and the hatred of humanity become intertwined. Many participants of my survey were explicitly misanthropic in their answers, some utilizing black metal as a way of channeling misanthropia and others claiming an enhancement of misanthropia through black metal.

Through these examples of misanthropy and individualism, it is apparent that black metal ideologies are directly involved in the experience of blackened walkers' iPod use. Either by 
being the reason for sonic control or the effect of sonic control, black metal values act as a central component to the iPod user's experience of blackened walking. It can be assumed then that blackened walkers and varying other music fans might differ in their approach to headphone use. By studying the headphone users and their blackened audiotopia in relation to the work of Bull and Prescott-Steed, I attempt to reach a deeper understanding of the black metal fan within headphone culture.

\section{Split or Blend}

All four experiences of the relationship of sonic imaginary and visual urban reality can be simply and broadly defined as daydreaming. Daydreaming falls somewhere between low and medium focus on the spectrum of consciousness, occupying a liminal state that is neither fully awake, with direct access to rational and logical thought, nor sleeping and unconscious. Instead, it remains a mix of both waking and sleeping, a distracted state of consciousness often involving free-flowing associative thought (Gelernter 2016, Singer 2014). The four experiences of the relationship of sonic and visual which I have compiled from my research can be further understood in relation to the spectrum of consciousness fabricated by David Gelernter (2016) in his book The tide of Mind: Uncovering the Spectrum of Consciousness (see figure 2).

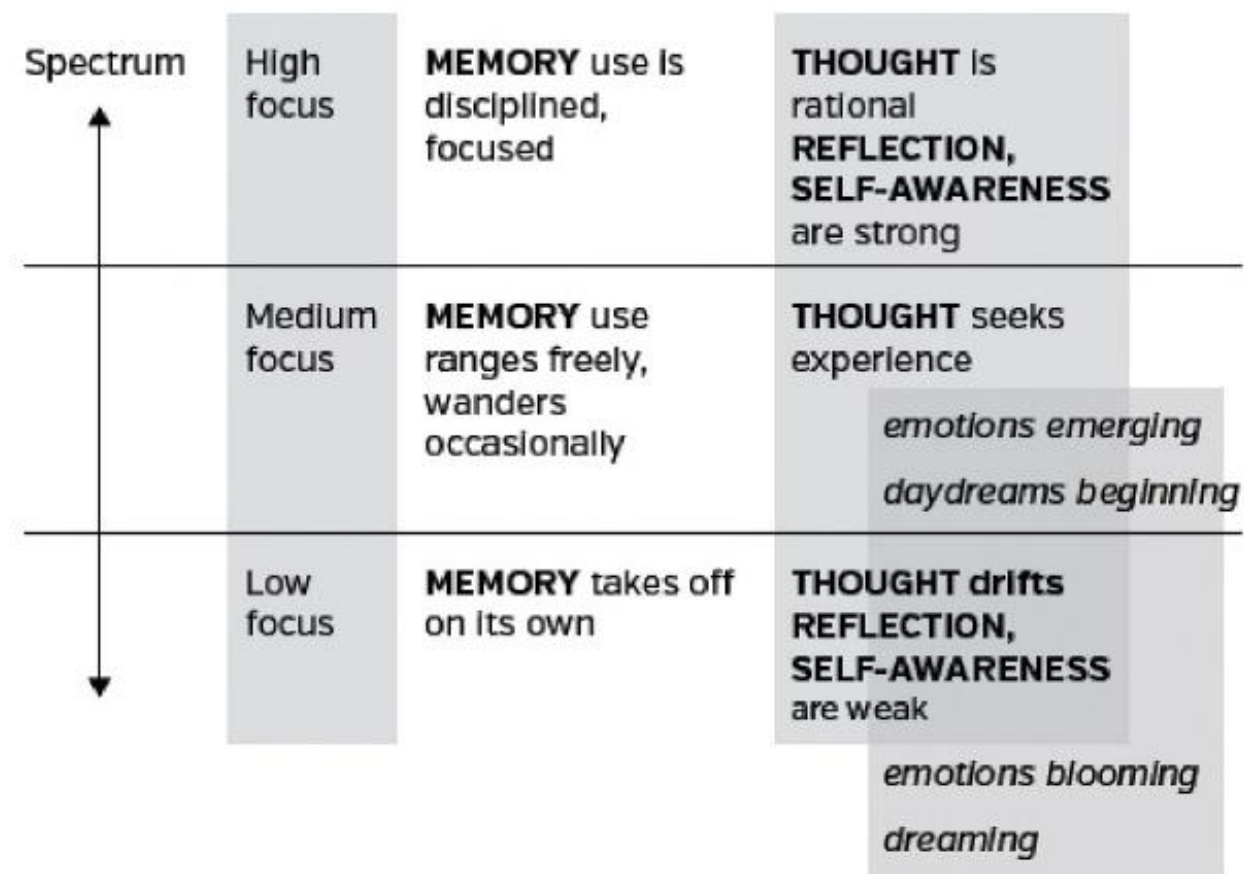

Figure 2: ‘A quick sketch’ The spectrum of consciousness (Gelernter 2016).

All four experiences fall between medium focus to low focus consciousness, the blending of visual and sonic being higher on the spectrum as it involves a more self-aware creativity, while the split is lower on the scale, the subject imagining the images they associate with the music.

\section{BLEND}




\section{Aestheticized real}

The aestheticized real is rather high on the spectrum of consciousness as it involves both visualand self-awareness, without rational and logical thought but with creative and associative thinking. This particular experience is not unique to the blackened walker, its namesake deriving from what Bull would call an aestheticization of the city where 'the terrains of imagination and the physical environment run into one another to the extent of being barely distinguishable' (Tim Ingold in Prescott-Steed 2012: 53).

In this state, the blackened walker aestheticizes the city, thus enhancing their perception of it in terms of traditional black metal imagery. Through this aestheticization, the participant strips the city of its cultural and anthropological significance for the purpose of artistic pleasure.

The Aestheticized real was the most popular experience in my survey. This may be due to it being the most flexible of both the blend and split, with the subject either subconsciously reacting to the music or consciously relating the music to their surroundings. A few participants conveyed how the music does not affect their thought process directly, but on more of a subconscious level. One participant declared, 'It acts like more of a soundtrack to whatever I'm doing at the time. It's mostly adding flavor to my current environment' and another: 'It's more of a reassuring background noise in such situations [walking through the city]'. Both of these participants reach cognitive control through sonic privatization, achieving the experience of the aestheticized real: a way of colouring or enhancing the urban space so to change one's perception of it. Uninterrupted mediated experience is achieved through sonic privatization, in both cases the participants maintaining a blackened audiotopia.

A clear awareness of aestheticizing the city was apparent in various responses from the survey. A few participants realized how black metal affected their perception of the city:

'[the city] feels much darker. You feel alone from people around you'

'I feel it [black metal] reflects the grim, functional beauty of the city'.

Both responses show awareness of the aestheticized real which has been obtained through headphone use. These participants are allowing the musical and extra-musical aspects of black metal to affect their imagination, words such as 'grim' and 'dark' as well as images such as solitude all reflect differing themes present in black metal ideology and visual culture.

In certain cases, black metal ideologies are firmly connected to the subject's experience of the city when in a blackened audiotopia. Aestheticization of urban space can afford feelings of empowerment and empowered isolation, cognitive effects which are directly connected to the individualism implicit in black metal. Several survey participants mentioned feeling powerful or linking the music with solitude and concentrating on the self. 'It makes time stand still for me, allows me to focus on the nuances of how the buildings look, how people move and behave... it creates a certain sense of being above it all'. For this participant, individualism and selfempowerment are evoked when listening to black metal. They aestheticize the city to make them feel like the all-powerful observer. Another response shows a different side of black metal ideology, that of isolation:

'Black metal intensifies the feeling of solitude and sharpens my visual awareness, especially in large open spaces...music in general serves as a kind of distancing barrier 
between me and others when I'm out, but black metal is probably the best at doing that since I become very focused on the thoughts and impressions it brings up'

This participant not only connects black metal with solitude, but also a distancing from humanity, one could even argue a triggering of solipsism. This solipsistic journey allows the subject to filter out any features of their external environment that they do not like and enhance their perception of the urban through the 'thoughts and impressions' which black metal conjures. Here, the aestheticized real is even allowing the blackened walker to use the music to create an imaginary isolated space through aestheticization of the city.

Many participants connected the black metal ideology of misanthropy to their experience of their blackened audiotopia. Some were very explicit in their answers, one respondent declared: 'the all pervading frost and hatred in BM [black metal] makes me realize just how much I hate the human pestilence'. Here, the odious cold is distinctly linked with a cold-hearted loathing for humanity, who are envisioned as a disease. The subject consciously connects the music with its ideology misanthropy and relates it to their own environment, in this case the people walking past. Another uses the term misanthropic itself, and makes the connection between music, ideology and environment very clear, stating:

'I have had several experiences, especially when surrounded by a large group of people, that misanthropic element was enhanced. Khanate's 'Skin Coat' and Anaal Nathrakh's 'Submission is for the Weak' have had that effect a couple of times'.

Both of these comments reveal a process of connecting the sonic experience of listening to black metal with cognitive reactions based on the ideologies reflected in the music and/or lyrics.

The latter response refers to specific songs and lyrics which afford the participant a misanthropic perception of their environment. The first song mentioned entitled 'Skin Coat' refers to the murderous act of making a coat out of human flesh. This hypothetical fantasy is being used by the subject to project and control these feelings of misanthropia. The second song by Anaal Nathrakh is encapsulated in the title of the track 'Submission is for the weak' which is related to a misanthropic form of social Darwinism, a common theme in black metal. In this case, the belief is that the weak are 'surface shit' that should and will 'die on your knees' (Anaal Nathrakh 2001). The lyrics in both of these songs conjure feelings of misanthropia for the blackened walker who then projects them on the people surrounding them in the city, thus experiencing the aestheticized real.

In a similar way another participant makes a direct connection between the music and the city, also conjuring images of misanthropia and social Darwinism, declaring that 'I see the city as a living heaving infested corpse. Whilst avoiding contact as much as possible I see the dregs of society trudging through their daily struggle...' This respondent is aestheticizing the city in a metaphorical way as a 'living heaving infested corpse' and projecting their hatred onto the passersby who they refer to as 'the dregs of society'. The choice of words reflects a black metal aesthetic, with elements of death and a hatred of the weak.

\section{Transformed real}


Like the aestheticized real, the transformed real is relatively high on the spectrum of consciousness. The transformed real is a blended sonic-visual experience in which the blackened walker mutates the reality of the city through their music induced fantasies or imagination.

Similar to the misanthropic thoughts discussed in the previous section, one particular respondent even admitted to imagining images that emerge from these thoughts. When asked if they imagine the images/symbols that they associate with black metal when listening in the city, one subject replied:

'Absolutely. Humanity is garbage. Although I don't harbor any desire to hurt anyone, imagining some of the ferocity described in lyrics being wrought upon the city is amusing'.

Here the participant is unleashing their imagination onto the city. Black metal is inspiring them to conjure images which are then used to transform the city for a misanthropic pleasure. This seems to be a unique response to this survey. However, one can assume, that if the respondents were questioned more thoroughly on their remarks then the transformed real may have been a more popular experience among blackened walkers, especially those who relate to misanthropic themes.

\section{SPLIT}

The split experience differs from the blend whereby the subject blends together their visual and sonic worlds, in a visually aware daydream state. Instead, the split is where the sonic imaginary and visual urban reality are split from one another in a manner that reduces the subject's attention to their visual reality. In the two experiences of the split, both the unconscious and lucid imagined, the subject zones out from their surroundings completely, either falling deep into an unconscious daydream or a vivid conscious imagined.

\section{Unconscious Imagined}

In contrast to the experience of the blend, the unconscious imagined is very low on the spectrum of consciousness, being the closest to dreaming of the sonic-visual experiences. In the unconscious imagined the subject becomes unaware of their visual reality. Their mind wanders into a deep daydream state, which could be described as the unconscious mind which they enter and exit unaware of their specific thoughts. The subject of the unconscious imagined is almost sleepwalking, being unaware of their visual reality, while deep in their sonic imaginary. This is typified in one particular response where the subject states: 'I find myself zoning out to what I am listening to. Arriving at the destination questioning how I got here'. In the unconscious imagined, this participant is reaching ultimate escapism from reality, slipping deep into low spectrum consciousness with the aid of black metal music. A few participants referred to this experience in less explicit terms: 'It tends to make me less aware of what's going on around me, almost like I develop tunnel vision. I tend to get lost in my thoughts when I listen to BM [black metal]'. This participant shows a similar lack of awareness of visual reality, as they 'get lost in my thoughts', thus showing a low-level consciousness. Comparably, one participant simply 
stated that when listening to music that the city 'ceases to exist' and another 'The atmosphere of the music I listen to is such that it is all consuming'. Both of these responses allude to the unconscious imagined, being totally consumed by the music or being completely unaware of their surroundings.

\section{Lucid Imagined}

While the lucid imagined is higher on the spectrum of consciousness than the unconscious imagined, it is a lot lower than the blend experience, falling somewhere between low-middle and low focus. In this state, the blackened walker is self-aware and conscious of their daydreaming although splitting their eye and ear, concentrating only on the sonic imagined. The lucid imagined gets its name from lucid (nighttime) dreaming, whereby one is aware they are dreaming and thus can control their dream. Like lucid dreaming, the lucid imagined experience is one where the subject is aware of their daydreaming state and are in the position to control their imaginations. The main difference between the two splits of the sonic and visual is the awareness of daydreaming and more importantly whether the subject remembers their thoughts and feelings from their imagined. Whereas in the unconscious imagined the walker arrives at their destination with no memory of what happened between one point and another, the walker in the lucid imagined is aware of their journey, their imagination and their surroundings. Thus, walkers who experience this split of visual and sonic can recall the fantasies that they depicted when in a blackened audiotopia.

A few participants were short and simple in their responses, although clearly demonstrating a sonic and visual split. For example:

'Black metal lets me separate my thoughts from my environment (puts me in my own bubble)',

'When I listen it's like there's an energy around and for a sec there's only you and your thoughts'.

Both of these respondents show a clear knowledge of their use of music to withdraw from the perception of their material environment. The second participant demonstrates their use of the blackened audiotopia to block out external noise to create a sonic bubble which affords them isolation from the people around them. This connects the previously analysed individualism of black metal ideology with the blackened walker's desires for an isolated and individual listening experience.

Some responses showed more complexity in the blackened walker's experience. One participant explained how their environment affects their relationship of visual reality and sonic imagined:

'If the city is quiet, I find it easy to imagine these images, but if it's busy then I find myself only connecting with the darkness of the music, and sometimes the hatred towards other people'. 
This particular respondent refers to the busyness of their environment as an affective variable of whether they experience the lucid imagined or the aestheticized real. This answer is unique in its demonstration of affective variables, although one can assume that this is a common experience among headphone users as a busy street may involve more self-awareness and thus a more alert state of consciousness (blend), and a quiet street a lower state of consciousness can be slipped into as there are little external visual distractions (split).

When asked what images/symbols/ideas the participants connect to black metal, the top response was some aspect of nature, a common one being forests and differing images of winter: Nordic snow-covered landscapes. Of the other responses, the answers included images of satanism, paganism, nihilism, misanthropy, individualism and death. Along with these themes when asked whether they imagine such images when in the city listening to black metal, various comments included a rejection of the urban through an attraction to nature. Some answered simply, showing a direct connection between the music and nature, '[I imagine] Cold and forest yes'. Another comment shows a negation of the urban environment through feelings of nostalgia for nature, 'Some of it makes me nostalgic for living in the countryside and the more remote places I went to'. The relationship between the sonic imaginary and visual urban reality has split through two opposing concepts presented by the eye and the ear: thus, experiencing the lucid imagined. This describes the creation of a rupture in consciousness, through which the sonic imaginary and the urban visual reality are torn from one another. Prescott-Steed (2013) similarly discovered a rupture in his personal case study where he observes the fissure between his imagined Nordic landscape and his urban material reality, a split between city and nature previously mentioned. By imagining a rural landscape in place of the urban reality, the subject is rejecting the urban. Furthermore, it could be argued that all experiences of the lucid imagined are a conscious rejection of the urban reality, as the blackened walker prefers to escape into a music-induced imagined state rather than blend their sonic and visual experiences to aestheticize or transform the city with thought and feeling.

\section{The Blackened Walker: Place and Space.}

It is important to connect the differing experiences of the relationship of sonic and visual to the experience of space. When one pictures the city dweller walking through urban space, the concept of the flâneur comes to mind. The flâneur is an observer of urban or social space who takes pleasure in gazing on passersby. Bull expresses the perspective that the flâneur is in fact in contrary position to iPod culture and the iPod user (Bull 2007: 39). He claims that the iPod user is using an audiotopia as a coping strategy, a way of dealing with 'urban chill', the spaces which we walk through and the people we pass which we are distanced and disassociated from (Bull 2007). In a general sense, I agree with Bull that the flâneur is in opposition to the headphone user. However, there are two experiences of the sonic-visual that I have observed which could be connected to that of the flâneur. The experiences of the blend, both the transformed real and aestheticized real could be argued to share attributes with the flâneur. As the flâneur is concerned with observing society, so too could the walker experiencing the blend, either aestheticizing society, or taking their observation a step further, inflicting fantasy onto the city or passersby. The complexity of the flâneur character does however weaken this connection, as the flâneur is often described as not only observing society, but also attempting to understand an individual by putting themselves in somebody else's shoes (Ekman 2013). In relation to the 
blackened walker, the flâneur is contrasting, as the misanthropic walker does not attempt to understand humanity, but, instead, condemn it.

Contrary to flâneurism, blackened walkers tend to either appropriate or reject urban space. One final concept that can help to understand blackened walking is Marc Augé's 'nonplace' (1992). Nonplace is a term used to describe the spaces which are 'semiologically denuded' (Ekman 2013: 159). Nonplaces motorways and service stations, shopping centres and entertainment complexes. Blackened walkers are able to reconfigure space into non-places, stripping spaces of anthropological and cultural significance. The blend achieves the nonplace through aestheticizing or transforming the city for the subjects own pleasure, and the split through the negation of space altogether. The blend's nonplace can also be described as the dual movement of sonic deterritorialization and reterritorialization (Thibaud 2003). When the iPod user puts on their headphones sonic deterritorialization occurs, and when they apply their own musical subjective meaning to the space, the sonic reterritorialization commences. In contrast, the split's nonplace, only strips a place of meaning and then negates its significance further therefore leaving the space in a deterritorialized state.

\section{Conclusion}

The concept of blackened walking has acted as a gateway for exploration into the complex relationship of two worlds, aural and visual, imagined and material. I have constructed four categories for this sonic-visual relationship which are divided into a split or blend. The aestheticized real and the transformed real describe the two experiences of the blend. The former enhances the city with an artistically pleasing perception, perhaps matching together the coldness of black metal with urban chill, and the latter molds the city with imagined happenings, exemplified often in misanthropic fantasizing: inflicting ill upon passersby. The split is categorized as either the unconscious imagined or the lucid imagined and can be understood as a negation of the urban reality. The unconscious imagined defines the 'zoning out' experience, where the subject splits the sonic and visual, negating visual reality, while delving into the deep imaginary. In the lucid imagined, the blackened walker focuses on an imagined landscape or scenario, visualizing, for example, a dense dark forest or the hardened snow crunching under foot.

Through the analysis of the differing experiences of blackened walkers, I have observed that the majority, if not all, of the walkers engage in a blackened audiotopia as a form of escapism. These iPod users almost all long for freedom from their urban reality via a daydream state. Whether by categorizing their desires as either a need for mood maintenance, stressdecrease, or to aid misanthropic or individualistic thoughts, blackened walkers withdraw themselves from reality so to immerse themselves in a more familiar world, that of black metal. Surrounded by the music they love, in an aestheticized or imagined world, the blackened walker achieves a blackened escapism and audiotopia.

The main difference between the blackened walker and the headphone user of no specific music, is the strong link between black metal music and its ideologies and visual culture. The subjects of my survey have confirmed this link as the walkers attach the significations of the music to their aestheticization or imagination. This is typified in two examples of how black metal signification and ideology affect both the split and blend experiences: 
'...it [listening to black metal] helps me feel both connected and disconnected from reality. In the mornings the city is pretty deserted, and I can almost imagine I'm not in the city at all and I'm somewhere else more suited to traditional "black metal imagery"'

'I often become immersed in the atmosphere of the music which affects my perception of my environment...'

Both of these examples demonstrate the connection between black metal and its ideologies and imagery, as fans of the music enter into an audiotopia stimulated by the significations of black metal music and culture.

Through categorizing the experiences of the blackened walker I hope to have shed light on the micro specific of their relationship with space and place. I have argued that the walker through either a split or blend of sonic and visual, or through a shift between both in a single experience, often strips the space through which they walk from cultural and anthropological significance in an act of sonic deterritorialization. In doing so, the space takes on a new significance as a nonplace, one that lacks semiological meaning. This allows the iPod user to either reterritorialize the space in terms of traditional black metal imagery or negate that space altogether.

In summary, the blackened walker seeks escapism from or an enhancement of reality, and achieves it through black metal listening: negating, transforming and aestheticizing urban space to create a blackened experience.

\section{References}

Anaal Nathrakh (2001). The Codex Necro. Essex: Mordgrimm.

Augé, Marc (1992) Non Places: Introduction to an Anthropology of Supermodernity. London: Verso.

Bull, Michael and Back, Les. (2003) The Auditory Culture Reader. Oxford: Berg.

Bull, Michael (2012), 'iPod Culture: The Toxic Pleasure of Audiotopia', The Oxford Handbook of Sound Studies, pp.526-543.

Bull, Michael (2014), 'iPod Use, Mediation, and Privatization in the Age of Mechanical Reproduction', Mobile Music Studies, Sumanth Gopinath and Jason Stanyek (eds.), pp.103-117. Oxford: Oxford University Press.

Bull, Michael (2007), Sound Moves: iPod Culture and Urban Experience, Oxon: Routledge.

Ekman, Ulrik (2013), Throughout: Art and Culture Emerging with Ubiquitous Computing, Cambridge: MIT Press.

Gelernter, David (2016), The Tides of Mind: Uncovering the Spectrum of Consciousness, New York: Liveright Publishing Corporation. 
Hagen, Ross (2011), 'Musical Style, Ideology, and Mythology in Norwegian Black Metal', Metal Rules the Globe: Heavy Metal music around the world, Jeremy Wallach, Harris M. Berger, and Paul D. Greene (eds.), pp.180-199. London: Duke University Press.

Itkowitz, Jordan (2010), A Tribute To Our Glourious Dead. Teeth of the Divine. http://www.teethofthedivine.com/featured/interview-with-wodensthrone/

Kahn-Harris, Keith (2007), Extreme Metal: Music and Culture on The Edge. Oxford: Berg Moynihan, Michael and Søderlind, Didrik (1998), Lords of Chaos: The Bloody Rise of the Satanic Metal Underground. Port Townsend: Feral House.

Patterson, Dayal (2013), Black Metal: Evolution of the Cult, Port Townsend, Washington: Feral House

Prescott-Stead, David (2013), 'Frostbite On My Feet, Representations of Walking in Black Metal Visual Culture', Amelia Ishmael, Zareen Price, Aspasia Stephanou, Ben Woodard (eds.) Helveta, 1, pp.45-68.

Singer, Jerome L (2014), Daydreaming and Fantasy, Hove:Routledge.

Thibaud, Jean-Paul (2003), 'The Sonic Composition of the City', Michael Bull and Les. Back (eds.) The Auditory Culture Reader, pp.329-341. Amsterdam: Berg Publishers.

Venkatesh, Vivek, Podoshen Jeffrey S., Urbaniak Kathryn and Wallin, Jason J. (2014) 'Eschewing Community: Black Metal', Journal of Community and Applied Social Psychology 25, pp.66-81.

VICE (2011), True Norwegian Black Metal | VICE, [Dcoumentary], available at: https://youtu.be/32iX5lbVDto 